\title{
Effectiveness of Digital Education on Communication Skills Among Medical Students: Systematic Review and Meta-Analysis by the Digital Health Education Collaboration
}

Bhone Myint Kyaw ${ }^{1}$, MBBS, MSc, PhD; Pawel Posadzki ${ }^{1}$, PhD; Sophie Paddock ${ }^{2}$, MCE, MBBS; Josip Car ${ }^{1}$, MD, PhD, FRCP, FFPH; James Campbell ${ }^{3}$, MSc, MPH; Lorainne Tudor Car ${ }^{4,5}$, MSc, MD, PhD

\footnotetext{
${ }^{1}$ Centre for Population Health Sciences, Lee Kong Chian School of Medicine, Nanyang Technological University, Singapore, Singapore

${ }^{2}$ Norfolk \& Norwich University Hospital, Colney Lane, Norwich, United Kingdom

${ }^{3}$ Health Workforce Department, World Health Organization, Geneva, Switzerland

${ }^{4}$ Family Medicine and Primary Care, Lee Kong Chian School of Medicine, Nanyang Technological University, Singapore, Singapore

${ }^{5}$ Department of Primary Care and Public Health, School of Public Health, Imperial College London, London, United Kingdom
}

\section{Corresponding Author:}

Lorainne Tudor Car, MSc, MD, PhD

Family Medicine and Primary Care

Lee Kong Chian School of Medicine

Nanyang Technological University

11 Mandalay Road

308232

Singapore,

Singapore

Phone: 6569041258

Email: lorainne.tudor.car@ntu.edu.sg

\section{Abstract}

Background: Effective communication skills are essential in diagnosis and treatment processes and in building the doctor-patient relationship.

Objective: Our aim was to evaluate the effectiveness of digital education in medical students for communication skills development. Broadly, we assessed whether digital education could improve the quality of future doctors' communication skills.

Methods: We performed a systematic review and searched seven electronic databases and two trial registries for randomized controlled trials (RCTs) and cluster RCTs (cRCTs) published between January 1990 and September 2018. Two reviewers independently screened the citations, extracted data from the included studies, and assessed the risk of bias. We also assessed the quality of evidence using the Grading of Recommendations, Assessment, Development, and Evaluations assessment (GRADE).

Results: We included 12 studies with 2101 medical students, of which 10 were RCTs and two were cRCTs. The digital education included online modules, virtual patient simulations, and video-assisted oral feedback. The control groups included didactic lectures, oral feedback, standard curriculum, role play, and no intervention as well as less interactive forms of digital education. The overall risk of bias was high, and the quality of evidence ranged from moderate to very low. For skills outcome, meta-analysis of three studies comparing digital education to traditional learning showed no statistically significant difference in postintervention skills scores between the groups (standardized mean difference [SMD] $=-0.19 ; 95 \% \mathrm{CI}-0.9$ to $0.52 ; I^{2}=86 \%, \mathrm{~N}=3$ studies $[304$ students]; small effect size; low-quality evidence). Similarly, a meta-analysis of four studies comparing the effectiveness of blended digital education (ie, online or offline digital education plus traditional learning) and traditional learning showed no statistically significant difference in postintervention skills between the groups $\left(\mathrm{SMD}=0.15 ; 95 \% \mathrm{CI}-0.26\right.$ to $0.56 ; I^{2}=86 \% ; \mathrm{N}=4$ studies [762 students]; small effect size; low-quality evidence). The additional meta-analysis of four studies comparing more interactive and less interactive forms of digital education also showed little or no difference in postintervention skills scores between the two groups ( $\mathrm{SMD}=0.12 ; 95 \% \mathrm{CI}$ : -0.09 to $0.33 ; I^{2}=40 \% ; \mathrm{N}=4$ studies [ 893 students]; small effect size; moderate-quality evidence). For knowledge outcome, two studies comparing the effectiveness of blended online digital education and traditional learning reported no difference in postintervention knowledge scores between the groups ( $\mathrm{SMD}=0.18$; $95 \% \mathrm{CI}$ : -0.2 to 0.55 ; $I^{2}=61 \% ; \mathrm{N}=2$ studies [292 students]; small effect size; low-quality evidence). The findings on attitudes, satisfaction, and 
patient-related outcomes were limited or mixed. None of the included studies reported adverse outcomes or economic evaluation of the interventions.

Conclusions: We found low-quality evidence showing that digital education is as effective as traditional learning in medical students' communication skills training. Blended digital education seems to be at least as effective as and potentially more effective than traditional learning for communication skills and knowledge. We also found no difference in postintervention skills between more and less interactive forms of digital education. There is a need for further research to evaluate the effectiveness of other forms of digital education such as virtual reality, serious gaming, and mobile learning on medical students' attitude, satisfaction, and patient-related outcomes as well as the adverse effects and cost-effectiveness of digital education.

(J Med Internet Res 2019;21(8):e12967) doi: $10.2196 / 12967$

\section{KEYWORDS}

randomized controlled trials; effectiveness; systematic review; communication skills; medical education

\section{Introduction}

Both qualitative and quantitative researchers have intensely studied the importance of communication between patients and doctors since the 1970s. Within health care, where an individual explores the unknown environment of one's own health and disease, effective communication skills can positively affect a number of health outcomes including better emotional and physical health, higher symptom resolution, improved pain control, greater treatment compliance, and enhanced patient satisfaction [1]. Furthermore, studies have reported reductions in emotional distress, levels of discomfort, concerns, fear, hopelessness, grief, depression, or health services utilization as a result of effective communication [2,3]. Communication involves respecting the persons' dignity, integrity, and autonomy [4,5] as well as an ability to explore and discuss their expectations or wishes in a warm, nonjudgmental, and friendly manner. Effective communication (verbal and nonverbal) includes traits such as empathy, understanding, active listening, and the ability to meet patients' needs and emotionally charged information [6]. In clinical practice, effective communication also requires features needed for effective symptom control such as honesty, open disclosure, an ability to gain trust [7], and influence over patient behavior [8]. These communication skills are essential in building the doctor-patient relationship or "therapeutic alliance." Finally, physicians have legal, ethical, and moral obligations to demonstrate a variety of communication skills including the ability to gather information, formulate an accurate diagnosis, provide therapeutic instructions and medical advice, communicate risk, and deliver health-related news to the patients $[9,10]$.

Communication skills training is recognized as an important component of the curricula in undergraduate and postgraduate medical education and is endorsed, for example, by the UK General Medical Council, which states that students should be able to "communicate clearly, sensitively and effectively with patients, their relatives and colleagues" [11]. The optimal method of teaching and learning communication skills is considered a direct observation of the student's performance, followed by feedback from an experienced tutor [12,13]. This form of small-group teaching requires intensive planning and resources including simulated patients and experienced tutors. The lack of standardization within these patients and tutors can result in unequal learning outcomes.
Digital education encompasses a broad spectrum of didactic interventions characterized by their technological content, learning objectives/outcomes, measurement tools, learning approaches, and delivery settings. Digital education includes online digital education, offline digital education, massive open online courses, learning management systems, mobile digital education (mobile learning or m-learning), serious games and gamification, augmented reality, virtual reality, or virtual patient (VP) [14-17].

For medical students learning communication skills, digital education offers self-directed, flexible, and interactive learning (didactic); novel instructional methods; and the ability to simulate and rehearse different clinical scenarios (experiential learning) [18]. For instance, online digital education could be a potential method of delivering the theoretical concepts that underpin communication skills. Virtual patient simulations may also be useful in clinical scenarios that are difficult to replicate with standardized patients, such as communication with patients who have rare conditions, speech disorders, and neurological diseases. Digital education can be utilized flexibly and for an unlimited number of times alongside traditional methods such as role play with standardized patients, allowing students to practice their skills "interchangeably." For educators, digital education offers the potential to free up time, save manpower and space resources, automate evaluation and documentation of students' progress, and receive feedback from the students [19].

Given the shortage of trained and experienced health care educators to deliver communication skills training, digital education may be a novel, cost-effective modality. To the best of our knowledge, there is no similar systematic review assessing the effectiveness of digital education for medical students' communication skills training. The aim of this research was to evaluate the effectiveness of digital education compared with various controls in improving knowledge, skills, attitudes, and satisfaction of medical students learning communication skills. In doing so, we aim to fill an important gap in the literature.

\section{Methods}

For this systematic review, we adhered to the Preferred Reporting Items for Systematic Reviews and Meta-Analyses Guidelines and the Cochrane Handbook for Systematic Reviews 
of Interventions [20]. For a detailed description of the methodology, please refer to the study by Car et al [21].

\section{Eligibility Criteria}

We considered studies eligible for inclusion if they were randomized controlled trials (RCTs) of any design and of any type of digital education including blended education (combination of digital education and traditional learning) for medical students (ie, preregistration); measuring any of the primary outcomes, ie, knowledge, skills, attitudes, satisfaction; or measuring secondary outcomes, ie, patient-related outcomes, adverse effects, or costs (economic evaluations). We included studies if the studies compared: digital education versus traditional learning, digital education versus other forms of digital education, digital education versus no intervention, blended digital education versus traditional learning, and blended digital education versus no intervention.

We did not exclude participants based on age, gender, or any other sociodemographic factor. If data within a study included both preregistration (undergraduate level) and postregistration (postgraduate level) students, the study was included if these data were presented separately. We did not impose any language restrictions. Nonrandomized studies or trials of postgraduates including continuous professional development; continuous medical education; and students of traditional, alternative, and complementary medicine were excluded.

\section{Search Strategy and Data Sources}

We searched the following databases from January 1, 1990, to September 20, 2018, for all relevant digital education trials: Cochrane Central Register of Controlled Trials (Wiley), Educational Resource Information Centre (Ovid), Embase (Elsevier), Cumulative Index to Nursing and Allied Health Literature (Ebsco), MEDLINE (Ovid), PsychINFO (Ovid), and Web of Science Core Collection. We also searched the two trials registers-International Clinical Trials Registry Platform and metaRegister of Controlled Trials - to identify unpublished trials. We selected 1990 as the starting year for our search because the use of computers was limited to very basic tasks prior to this year. There were no language restrictions. We searched reference lists of all the studies that we deemed eligible for inclusion in our review and relevant systematic reviews. For a detailed search strategy for MEDLINE, please see Multimedia Appendix 1.

\section{Data Selection, Extraction, and Management}

We merged the search results from the databases using EndNote software [computer software] (Version X.7.8. Philadelphia, PA: Clarivate Analytics) and removed duplicates of the same record. Three reviewers (PP, SP, and BK) independently screened titles and abstracts to identify potentially eligible articles. They then read the full-text versions of these studies and assessed them independently against the inclusion and exclusion criteria. Any disagreements about whether a study meets the eligibility criteria were resolved through discussion among the two review authors. A third review author's opinion was sought to resolve any disagreements between two review authors. If a study had more than one intervention group, for comparison, we chose the relevant digital education group (ie, more interactive intervention) against the least interactive controls. "Interactivity" referred to "the degree of control or adaptiveness a user might have with a system, without necessarily having to give a response" [22], and we applied this definition of "interactivity" throughout the review. For each of the included studies, two reviewers independently extracted data related to the characteristics of population, intervention, comparators, outcome measures, and study design, and any discrepant opinions were resolved by discussion.

\section{Assessment of Risk of Bias}

Three review authors (PP, SP, and BK) independently assessed the risk of bias of the included studies using the Cochrane Risk of Bias Tool [20]. Disagreements between the reviewers were resolved by discussion. We appraised the following domains: random sequence generation, allocation concealment, blinding (participants, personnel and outcome assessors), completeness of outcome data, selective outcome reporting, and other biases. Each item was judged as having high, low, or unclear risk of bias based on the definitions provided by Higgins and Green [20]. For cluster RCTs, the risk of bias assessment also focused on recruitment bias, baselines imbalance, loss of clusters, incorrect analysis, and comparability with individually randomized controlled trials [23]. We incorporated the results of the risk of bias assessment into the review using a graph and a narrative summary.

\section{Data Synthesis and Analysis}

For continuous outcomes, we reported postintervention mean scores and SD along with the number of participants in each intervention group. We reported postintervention mean outcome data to ensure consistency across the included studies, as most of the included studies (92\%) reported postintervention data. We presented outcomes using postintervention standardized mean difference (SMD) and interpreted the effect size based on the Cohen rule of thumb (ie, with 0.2 representing a small effect, 0.5 representing a moderate effect, and 0.8 representing a large effect) [20,24]. If studies had multiple arms, we compared the most interactive intervention arm to the least interactive control arm and assessed the difference in postintervention outcomes.

For dichotomous outcomes, we summarized relative risks and associated $95 \%$ CIs across studies. Subgroup analyses were not feasible due to the limited number of studies within respective comparisons and outcomes. We used a random-effects model for meta-analysis. We used the $I^{2}$ statistic to evaluate heterogeneity, with $I^{2}<25 \%, 25 \%-75 \%$, and $>75 \%$ representing low, moderate, and high degree of inconsistency, respectively. The meta-analysis was performed using Review Manager 5.3 [25]. We reported the findings in line with the PRISMA reporting standards [26].

The three authors (SP, PP, and BK) independently assessed the overall quality of the evidence in accordance with the Grading of Recommendations, Assessment, Development and Evaluations criteria [27]. The following criteria were considered: limitations of studies (risk of bias), inconsistency, indirectness, imprecision and publication bias, and downgrading the quality where appropriate. We did this for all primary and secondary outcomes reported in the review. We rated the quality of 
evidence for each outcome as "high," "moderate," and "low." We prepared "Summary of findings" tables for each comparison to present the findings and rated the quality of the evidence for each outcome (Multimedia Appendices 2-4). We were unable to pool the data statistically using meta-analysis for some outcomes (eg, attitude and satisfaction) due to high heterogeneity in the types of participants, interventions, comparisons, outcomes, outcome measures, and outcomes measurement instruments. We presented those findings in the form of a narrative synthesis. We used the standard method recommended by Higgins et al [20] to synthesize and represent the results.

\section{Results}

\section{Overview}

We identified 44,054 records overall from electronic database searches. We excluded 43,287 references after screening titles and abstracts and retrieved 28 studies for full-text evaluation, of which 12 studies met the inclusion criteria [28-39] and were included in the review (Figure 1). The total number of students was 2101 .

We present details of the included trials in Table 1. The included studies were published between 2000 and 2018; of these, nine were RCTs, two were cluster RCTs [31,38], and one was a factorial-design RCT [30]. The studies originated from Australia [28], China [39], Germany [30,37], and the United States
[29,31-36,38]. The sample sizes in the included studies ranged from 67 to 421 medical students, and they were in their first, second, third, and fourth year of studies. The included studies focused on different modalities of digital education. For instance, five studies (41.7\%) [28,33,35,36,38] used VP, whereas the remaining seven studies $(58.3 \%)$ used online modules; in addition, five studies (41.7\%) used traditional learning in addition to digital education, that is, blended digital education $[30,31,34,37,39]$. Two studies $(22.2 \%)$ had more than one intervention arm $[29,30]$. The content of those interventions also differed from history-taking and basic communication skills [28,30,33,36,37], cross-cultural communication [32], ethical reasoning [34], suicide risk management [35], interprofessional communication [38], ophthalmology-related communication skills training [39], and substance abuse-related communication [31] to end-of-life support [29]. Comparison groups ranged from other digital education such as virtual patient [28], online learning [38], traditional learning (written curriculum, didactic lecture, oral feedback, and standardized patient) [29,31-34,36,37,39], video group [35], or no intervention [30]. Outcomes were measured using a range of tools including scales, surveys, checklists, Likert scales, and Objective Structured Clinical Examination (OSCE), questionnaires; seven studies $(58.3 \%)$ reported some type of validity evidence (ie, validity, reliability, and responsiveness for those measurement tools) [28,30,31,33-35,39]. 
Figure 1. Preferred Reporting Items for Systematic Reviews and Meta-Analyses flow diagram. RCT: randomized controlled trial.

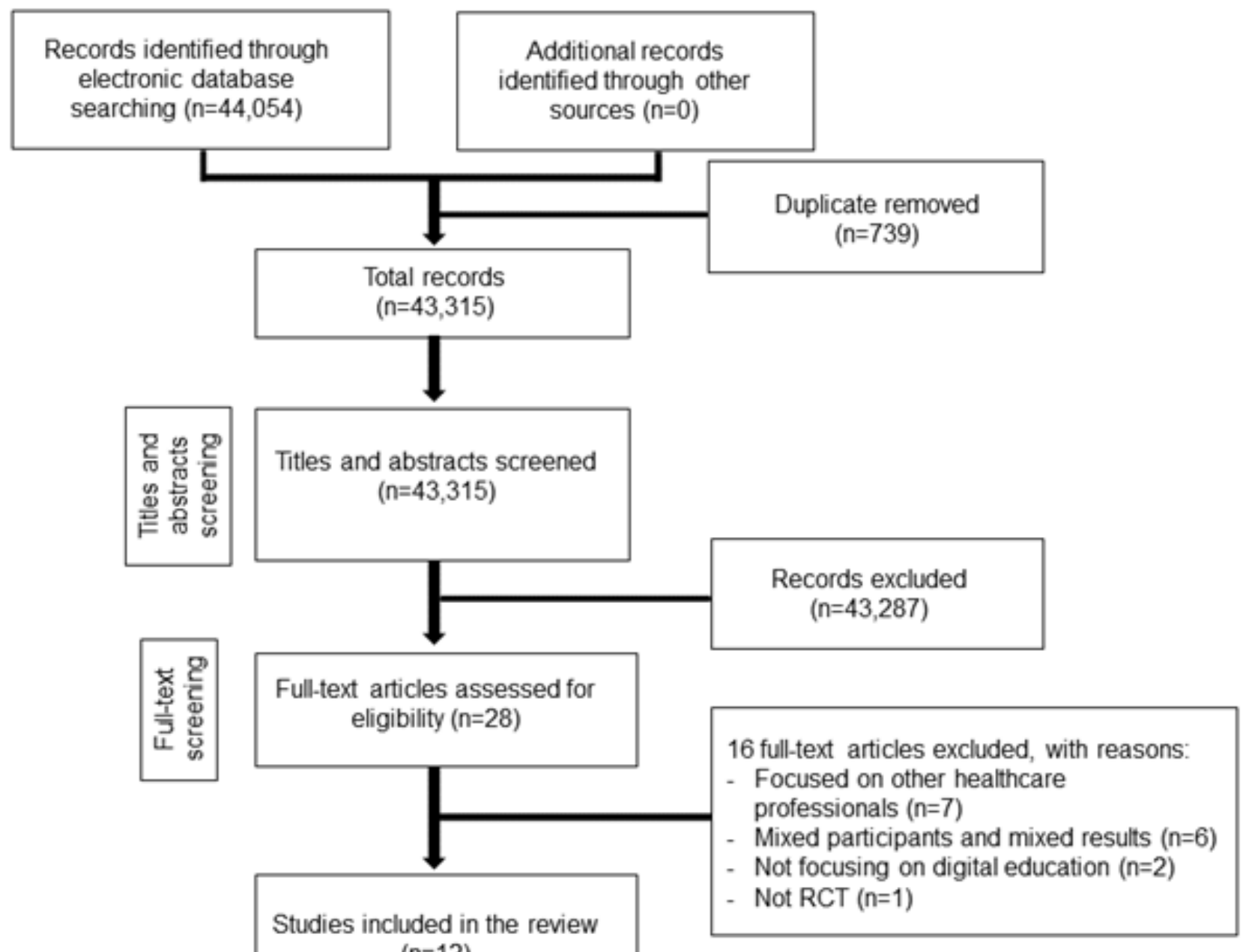


Table 1. Main characteristics of the included studies $(\mathrm{N}=12)$.

\begin{tabular}{|c|c|c|c|c|}
\hline $\begin{array}{l}\text { Study author names, } \\
\text { year, country, and design }\end{array}$ & $\begin{array}{l}\text { Number of partic- } \\
\text { ipants (year) }\end{array}$ & Intervention and comparator & $\begin{array}{l}\text { Outcome/measure- } \\
\text { ment instrument (va- } \\
\text { lidity, reliability) }\end{array}$ & $\begin{array}{l}\text { Results (postinter- } \\
\text { vention): SMD } \\
(95 \% \mathrm{CI})\end{array}$ \\
\hline
\end{tabular}

\section{Digital education versus traditional learning}

Chittenden et al, 121 (third)

2013 [29] US, RCT ${ }^{\mathrm{b}}$

Deladisma et al, $\quad 84$ (second)

2007 [33] US, RCT

Gartmeier et al,

168 (second and

2015 [30] Germany, third)

factorial RCT

Kaltman et al, 201899 (first)

[36] US, RCT

$\mathrm{IG}^{\mathrm{c}}$ : 45-min online module (multimedia)

$\mathrm{CG}^{\mathrm{d}}$ : Traditional learning (written curriculum)

\section{Blended digital education versus traditional learning}

Fleetwood et al, 2000 [34] US, RCT
173 (second)
Gartmeier et al, 2015 [30] Germany, third) factorial RCT

Lanken et al, 2015 [31] US, cluster RCT

370 (second and third)

Lee et al, 2015 [32]

US, mixed method RCT

Ruesseler et al, $2017 \quad 100$ (fourth) [37] Germany, RCT

Skills: checklist, Likert scale

Skills: $\mathrm{SMD}=0.00$ $(-0.46$ to 0.46$)$

Skills: Digital education=traditional learning

\section{IG: $\mathrm{VP}^{\mathrm{e}}$ simulation \\ CG: Traditional learning ( $\mathrm{SP}^{\mathrm{f}}$ consultation)}

IG1: 300-min online tutorial

CG1: No intervention (wait list)

IG: VP simulation (videobased)

CG: Traditional learning (usual curriculum)
IG: 45-min online module plus small group discussions (blended digital education) CG: 45-min traditional learning (group discussions)
Skills: survey, Likert Skills: $\mathrm{SMD}=-0.89$ scale (Cronbach al- $\quad(-1.35,-0.43)$ pha $=.87$ )

Skills: Likert scale (intraclass correlation $=0.54$ )

Skills: OSCE ${ }^{\mathrm{g}}$

Knowledge: $\mathrm{MCQ}^{\mathrm{h}}$ (exam)

Skills: checklist (validated)

Patient-related outcome (ie, patients' satisfaction): checklist (validated)

Skills: Likert scale

IG2: 300-min online tutoria and role play (blended digital education)

CG2: Role play

IG: 1-h online module and small group discussion (blended digital education) CG: Traditional learning (usual curriculum)

IG: 1-h online module (cultural competency and $\mathrm{PACT}^{\mathrm{i}}$ training plus standard curriculum)

CG: Traditional learning (standard curriculum)

IG: 1.5-h video-assisted oral Skills: OSCE feedback (blended digital education: video recorded role play with video-assisted oral feedback)

CG: Traditional learning (received direct oral feedback after role play )
Skills: survey Attitude: survey (Cronbach al$\mathrm{pha}=.89$ )

Knowledge: PACT (questionnaire) Skills: OSCE

Skills: $\mathrm{SMD}=0.92$ (0.51-1.33)

Skills: $\mathrm{SMD}=-0.08$ $(-0.28$ to 0.13$)$ 0.26 )

Skills: $\mathrm{SMD}=0.05$ $(-0.31$ to 0.41$)$
Skills: Digital education $<$ traditional learning

Narrative presentation

Skills: SMD $=0.33$ $(-0.16$ to 0.81$)$

Skills: Digital education=traditional learning

Knowledge: $\mathrm{SMD}=0.00(-0.30$ to tal 0.30) Skills: $\mathrm{SMD}=-0.20$ $(-0.50$ to 0.10$)$ Patients' satisfaction: $\mathrm{SMD}=-0.43$ $(-0.73$ to -0.13$)$

Narrative presentation

Skills: Digital education>traditional learning

Skills: Blended digital education=traditional learning

Attitude (toward the Attitude (toward the outoutcome): come): Blended digital ed$\mathrm{SMD}=0.05(-0.15$ to ucation=traditional learning

Knowledge: $\mathrm{SMD}=$ 0.38 (0.02-0.74)

Knowledge: Blended digital education $>$ traditional learning

Skills: Blended digital education=traditional learning

Skills: Blended digital education>traditional learning 


\begin{tabular}{|c|c|c|c|c|c|}
\hline $\begin{array}{l}\text { Study author names, } \\
\text { year, country, and design }\end{array}$ & $\begin{array}{l}\text { Number of partic- } \\
\text { ipants (year) }\end{array}$ & Intervention and comparator & $\begin{array}{l}\text { Outcome/measure- } \\
\text { ment instrument (va- } \\
\text { lidity, reliability) }\end{array}$ & $\begin{array}{l}\text { Results (postinter- } \\
\text { vention): } \mathrm{SMD}^{\mathrm{a}} \\
(95 \% \mathrm{CI})\end{array}$ & Effect estimate \\
\hline $\begin{array}{l}\text { Tang et al, } 2017 \text { [39] } \\
\text { China, RCT }\end{array}$ & 95 (fourth) & $\begin{array}{l}\text { IG: Online video plus team } \\
\text { discussion (blended online } \\
\text { digital education) } \\
\text { CG: Traditional learning } \\
\text { (didactic lecture) }\end{array}$ & $\begin{array}{l}\text { Attitude (toward the } \\
\text { outcomes): Likert } \\
\text { scale (three-point, } \\
\text { validated) } \\
\text { Students' satisfac- } \\
\text { tion (with the inter- } \\
\text { vention) Likert scale } \\
\text { (three-point, validat- } \\
\text { ed) }\end{array}$ & $\begin{array}{l}\text { Attitude (toward the } \\
\text { outcomes): favored } \\
\text { IG over CG }(P=.04) \\
\text { Students' satisfac- } \\
\text { tion (with the inter- } \\
\text { vention): no differ- } \\
\text { ence }(P=.61)\end{array}$ & $\begin{array}{l}\text { Attitude (toward the out- } \\
\text { comes): Blended online } \\
\text { digital education>tradition- } \\
\text { al learning } \\
\text { Students' satisfaction (with } \\
\text { the intervention): Blended } \\
\text { online digital educa- } \\
\text { tion=traditional learning }\end{array}$ \\
\hline
\end{tabular}

Digital education (more interactive) versus digital education (less interactive)

Bearman et al, 2001284 (not speci-

[28] Australia, RCT fied)

Chittenden et al, 121 (third)

[29] US, RCT

Foster et al, 2015

[35] US, RCT

67 (second)

Kron et al, 2017 [38] 421 (second)

US, mixed method

cluster RCT
IG: 1-h problem-solving VP CG: 1-h narrative VP bach alpha=83) CG: 1-h narrative VP

IG1: 45-min online module (multimedia)

Skills: checklist, Likert scale

IG2: 45-min online module (classic)

IG: Online-based VP simula-
tion
CG: Video group (online
module)
module)

IG: two VP simulations

CG: online module (multimedia computer-based learning) rapport subscale ly)

Students' satisfacbach alpha $=.89$ )

\section{Skills: OSCE}

Skills: $\mathrm{SMD}=-0.12 \quad$ Skills: Digital education $(-0.43$ to 0.2$) \quad$ (more interactive $)=$ digital education (less interactive)

Skills: $\mathrm{SMD}=0.00 \quad$ Skills: Digital education $(-0.42$ to 0.42$) \quad$ (more interactive) $=$ digital education (less interactive)

Skills: communica- $\quad$ Skills: $\mathrm{SMD}=0.33$ tion checklist and ( -0.15 to 0.82 ) (Cronbach alpha=.97 and .84 , respectiveStudents' satisfaction: $P=.007)^{\mathrm{j}}$ tion: survey (Cron-

Skills: $\mathrm{SMD}=0.26$ (0.06-0.45)

Attitude (toward the intervention): $\mathrm{SMD}=0.71(0.51-$ $0.91)$
Skills: Digital education (more interactive $)=$ digital education (less interactive)

Students' satisfaction: Digital education (onlinebased video group)>digital education (online-based VP simulation)

Skills: Digital education (more interactive) >digital education (less interactive) Attitude (toward the intervention): Digital education (more interactive) $>$ digital education (less interactive)

\footnotetext{
${ }^{a}$ SMD: standardized mean difference.

${ }^{\mathrm{b}} \mathrm{RCT}$ : randomized controlled trial.

${ }^{\mathrm{c}} \mathrm{IG}$ : intervention group.

${ }^{\mathrm{d}} \mathrm{CG}$ : control group.

${ }^{\mathrm{e}} \mathrm{VP}$ : virtual patient.

${ }^{\mathrm{f}} \mathrm{SP}$ : standardized patient.

${ }^{\mathrm{g}}$ OSCE: Objective Structured Clinical Examination.

${ }^{\mathrm{h}} \mathrm{MCQ}$ : multiple-choice questionnaire.

${ }^{\mathrm{i}}$ PACT: Problem Affect Concern Treatment.

${ }^{\mathrm{j}}$ Rating of the technology module overall.
}

In general, the risk of performance, detection, and attrition was predominantly low, and it was unclear or high for sequence generation bias, allocation concealment, and other bias. Reporting bias was judged as high in two (16.7\%) of the studies. For two cRCTs, the overall risk of bias was low or unclear. Four of the 12 included studies (33.3\%) were judged to have a high risk of bias in at least one domain (Figure 2). The quality of evidence ranged from moderate to very low due to study limitations, inconsistency, and imprecision across the studies. 
Figure 2. Risk of bias summary: review authors' judgements about each risk of bias item for each included study.

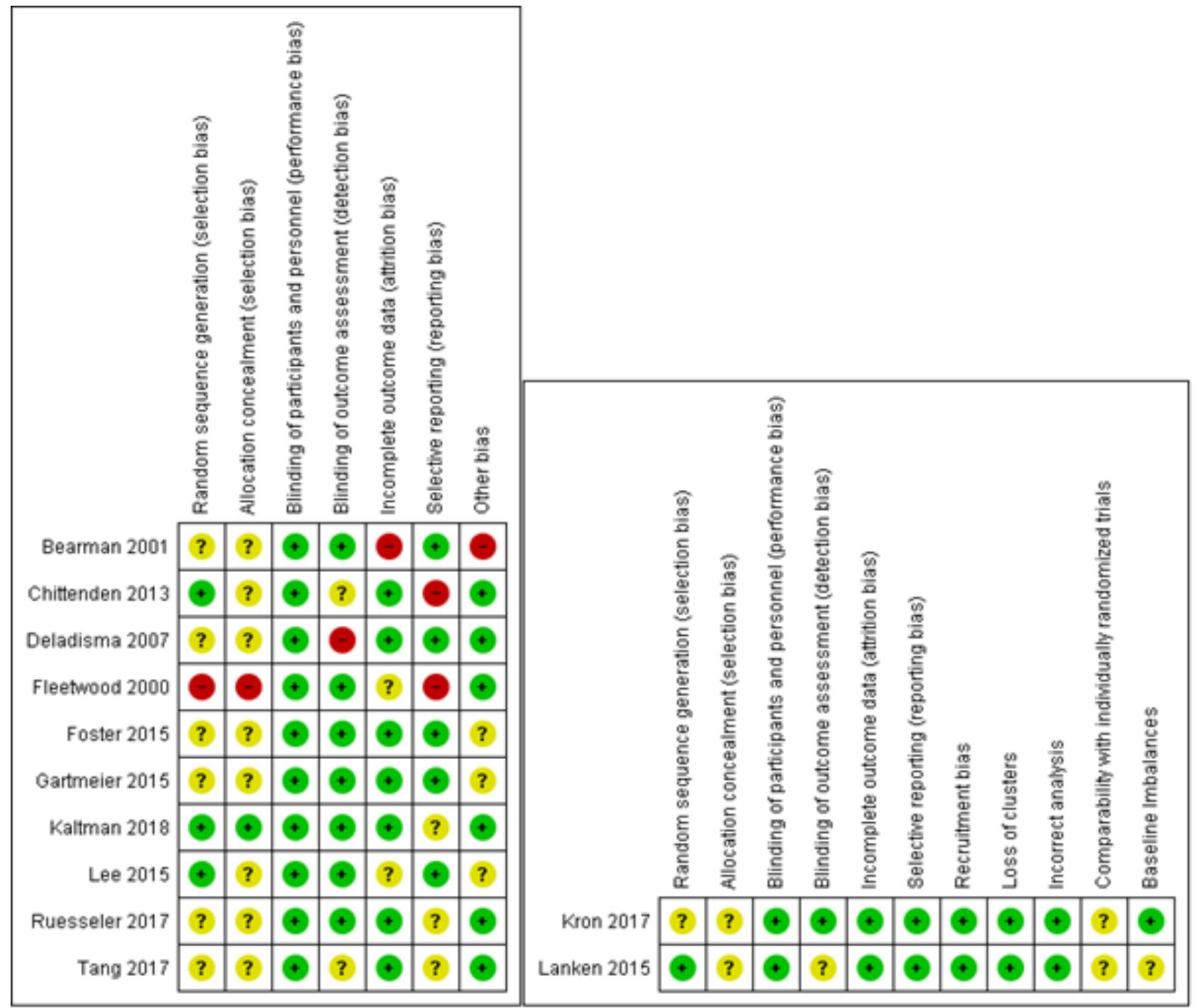

\section{Effect of the Interventions}

\section{Digital Education Versus Traditional Learning}

Four studies $[29,30,33,36]$ compared the effectiveness of digital education and traditional learning and reported on postintervention skills, attitudes, and satisfaction outcomes. For skills, there was no statistically significant difference between the digital education group (ie, online modules, tutorials, and virtual patient simulation) and the traditional learning group at postintervention ( $\mathrm{SMD}=-0.19 ; 95 \% \mathrm{CI}-0.9$ to $0.52 ; 3$ studies (304 students); $I^{2}=86 \%$; low-quality evidence; Figure 3). However, this finding had high imprecision with wide CIs, which also included a large effect size in favor of traditional learning as well as a moderate effect size in favor of digital education. The high observed heterogeneity was largely driven by a study comparing the effectiveness of VP simulation to simulated patient training [33]. The remaining two studies compared the effectiveness of online modules or VP simulation with more passive forms of traditional learning such as written materials or usual curriculum $[29,36]$. Findings from one study [30] favoring online digital education over no intervention could not be pooled with the other studies due to the lack of comparable numerical data.

None of the studies reported on knowledge, attitudes, satisfaction, adverse effects, patient outcomes, or cost outcomes. 
Figure 3. Forest plot of studies comparing digital education with traditional learning for postintervenion skill outcome, IV: inverse variance; random: random effect model.

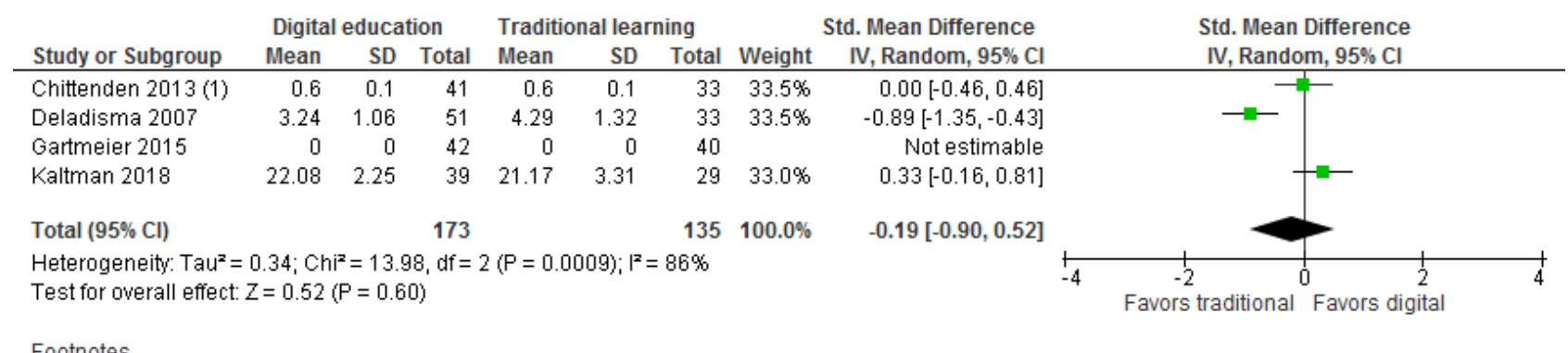

Footnotes

(1) Online module (multimedia) versus written curriculum

\section{Blended Digital Education Versus Traditional Learning}

Six studies [30-32,34,37,39] compared the effectiveness of blended digital education (ie, blended online or offline [video-based] digital education) and traditional learning and assessed students' postintervention knowledge, skills, attitude, and patient-related outcomes (ie, patients' satisfaction). For skills, there was no statistically significant difference between the groups at postintervention $(\mathrm{SMD}=0.15 ; 95 \% \mathrm{CI}-0.26$ to $0.56 ; I^{2}=86 \% ; 4$ studies (762 students); small effect size; low-quality evidence; Figure 4). The reported findings were imprecise due to wide CIs including moderate effect sizes in favor of blended digital education. Three studies included in the meta-analysis compared a blend of online modules and a small group discussion or standard curriculum with standard curriculum or small group discussions only [31,32,34]. The high observed heterogeneity was largely driven by a study comparing role play and video-assisted oral feedback to role play with oral feedback only, favoring blended digital education [37]. Findings from one study favoring a blend of online tutorials and role play could not be included in the meta-analysis due to the lack of comparable outcome data [30].
For knowledge, two studies compared the effectiveness between blended online digital education and traditional learning and reported no statistically significant difference between the groups at postintervention $(\mathrm{SMD}=0.18 ; 95 \% \mathrm{CI}-0.2$ to 0.55 ; $I^{2}=61 \% ; 292$ students; low-quality evidence; Figure 5). Wide CIs around the pooled estimate also included moderate effect size in favor of blended online digital education.

Two studies [31,39] assessed students' attitude toward the outcome (skills acquisition) at postintervention and reported no difference between the groups [31] or favored blended online education over traditional learning with didactic lectures $(P=.04)$ [39].

One study also assessed students' satisfaction with the intervention at postintervention and reported no difference between the groups $(P=.61)$ [39]. One study [34] reported patient-related outcomes (ie, patients' satisfaction) and compared a blend of online modules and small group discussions (ie, blended online digital education) with a control group of small group discussions only. The study reported slightly higher patients' satisfaction scores in the control group than in the blended online digital education (SMD $=-0.43$; 95\% CI -0.73 to -0.13). None of the studies reported on the adverse effects or cost outcomes.

Figure 4. Forest plot of studies comparing blended digital education with traditional learning for postintervention skill outcome. IV: inverse variance; random: random effect model; DE: digital education.

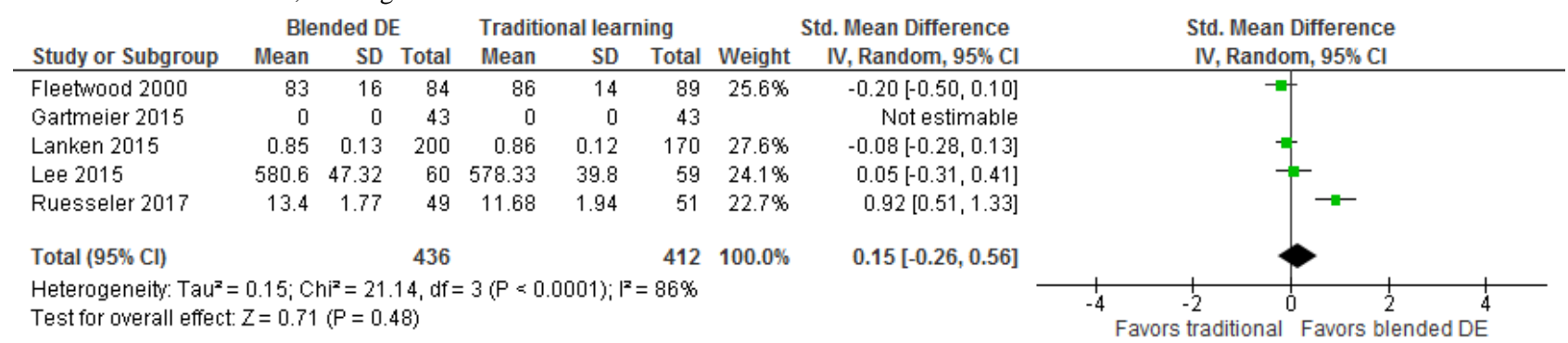

Figure 5. Forest plot of studies comparing blended online digital education with traditional learning for postintervenion knowledge outcome. IV: inverse variance; random: random effect model; DE: digital education.

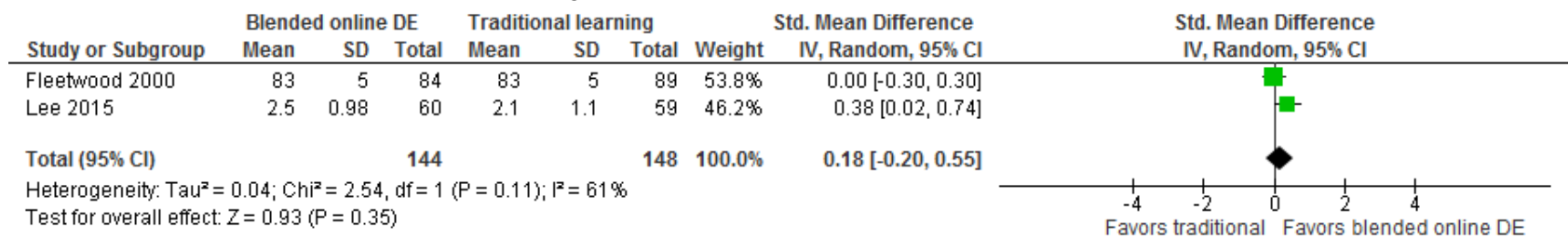




\section{Digital Education (More Interactive) Versus Digital Education (Less Interactive)}

Four studies $[28,29,35,38]$ compared the effectiveness of more and less interactive digital education and assessed postintervention skills, attitudes, and satisfaction. More interactive forms of digital education (ie, problem solving, VP simulation, and online multimedia modules) reported similar effectiveness or no difference in postintervention skills compared to less interactive forms of digital education (ie, narrative virtual patient simulation, online video-based learning, and classic online modules) $(\mathrm{SMD}=0.12,95 \% \mathrm{CI}-0.09$ to 0.33 ,
$I^{2}=40 \%, 4$ studies [893 students], moderate-quality evidence; Figure 6).

One study [38] assessed students' attitude towards the intervention and reported moderate beneficial effect on postintervention attitude scores in the VP group compared to the online module group (SMD=0.71; 95\% CI: 0.51-0.91). One study [35] assessed students' satisfaction and reported that students were more satisfied with VP simulation than the online-based video module $(P=.007)$. None of the studies reported on knowledge, adverse effects, patient outcomes, or cost outcomes.

Figure 6. Forest plot of studies comparing digital education (more interactive) with digital education (less interactive) for postintervention skills outcome. IV: inverse variance; random: random effect model; DE: digital education.

\begin{tabular}{lrrrrr} 
& \multicolumn{3}{c}{ DE (more interactive) } & \multicolumn{2}{c}{ DE (less inte } \\
Study or Subgroup & Mean & SD & Total & Mean & SD \\
\hline Bearman 2001 (1) & 36.4 & 5.5 & 79 & 37 & 4. \\
Chittenden 2013 (2) & 0.6 & 0.1 & 41 & 0.6 & 0.1 \\
Foster 2015 & 2.7 & 3.2 & 34 & 1.7 & 2.7 \\
Kron 2017 & 0.8 & 0.2 & 210 & 0.75 & 0.1 \\
Total (95\% Cl) & \multicolumn{3}{c}{364} \\
Heterogeneity: Tau ${ }^{2}=0.02 ; \mathrm{Chi}^{2}=4.98, \mathrm{df}=3(\mathrm{P}=0.17) ; \mathrm{I}^{2}=40 \%$ \\
Test for overall effect: $\mathrm{Z}=1.16(\mathrm{P}=0.25)$ \\
Footnotes \\
(1) VP (problem-solving) versus VP (narrative) \\
(2) Online module (multimedia) versus online module (classic)
\end{tabular}

\section{Discussion}

\section{Principal Findings}

This systematic review assessed the effectiveness of digital education on medical students' communication skills compared to traditional learning or other forms of digital education. We summarized and critically evaluated evidence for the effectiveness of digital education for medical students' communication skills training. Twelve studies with 2101 medical students met the eligibility criteria. We found low-quality evidence with wide CIs and high heterogeneity, showing no statistically significant difference between digital education and traditional learning in terms of communication skills. Blended digital education seems to be at least as effective as and potentially more effective than traditional learning for communication skills and knowledge. We also found no difference in postintervention skills between more and less interactive forms of digital education. Data on attitudes and satisfaction were limited and mixed. No study reported adverse or unintended effects of digital education nor conducted an economic evaluation. The majority of the studies $(\mathrm{N}=9,75 \%)$ had a high risk of bias. The quality of evidence ranged from moderate to very low due to the study limitations, inconsistency, and indirectness (Multimedia Appendices 2-4).

The included studies differed considerably in terms of intervention, comparators, and outcome measures used, showing a wide scope of potential for the use of digital education in communication skills training for medical students. However, limited primary studies consisting of data with high heterogeneity prevent us from drawing strong conclusions on the topic. Furthermore, seven $(58.3 \%)$ of the included studies failed to provide details of sample size or power calculations [28,29,32,35-37,39]. The included studies may have therefore

\section{Std. Mean Difference IV, Random, $95 \% \mathrm{Cl}$ \\ $-0.12[-0.43,0.20]$ \\ $0.00[-0.42,0.42]$ \\ $0.33[-0.15,0.82]$ \\ $0.26[0.06,0.45]$ \\ $0.12[-0.09,0.33]$}

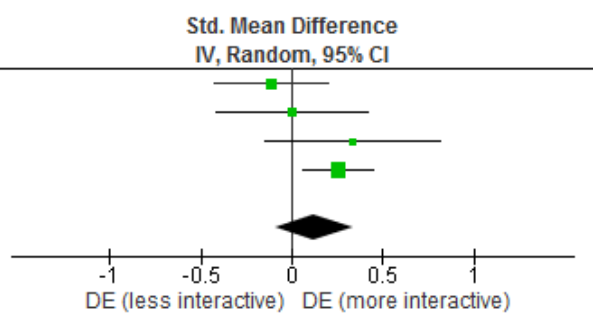

been underpowered and unable to detect change in learning outcomes. Finally, the effect sizes were typically small. Other limitations pertained to the risk of bias. Overall, four of the 12 included studies $(33.3 \%)$ were judged to have a high risk of bias in at least one domain.

The included evidence has some limitations. First, most of the studies were conducted in high-income countries (except one study that was conducted in China), which might further limit the transferability or applicability of the evaluated evidence in low- and middle-income countries. Second, the included studies focused only on specific forms of digital education such as online or offline digital education and VP simulation, and there is a need to explore the effectiveness of other forms of digital education such as virtual reality, serious gaming, mobile learning, and massive open online courses on the topic. Third, all included studies assessed short-term effectiveness of the interventions (ie, assessed effectiveness immediately after the intervention), and there is a need to assess long-term effectiveness of interventions through aspects such as knowledge retention and skills retention at 3-month or 6-month follow-ups. Lastly, the included studies mostly evaluated skills outcome, and there is limited evidence for other outcomes such as knowledge, attitude, satisfaction, adverse or untoward effects of the intervention, and patient and cost-related outcomes.

\section{Implications for Future Research}

We identified the need for further, more methodologically sound research that may lead to more conclusive findings. Studies identified in this review have many significant methodological weaknesses, from inadequate power to unclear theoretical underpinnings; insufficient description of educational interventions (complexity, duration and intensity); uncertainty of what constitutes a change (compared with baseline); little, 
if any, description of technical features; skills retention (follow-up); and comparability of the content delivered digitally or traditionally. The use of validated and reliable measurement tools is paramount to advancing the field [40], as its transparent description on the level of trialists' involvement in instructions, outcome(s) in the background, usability testing, and data protection policies could affect the results of the outcomes. Other important factors that need further research include the availability of infrastructure, financial incentives for learners, previous experience in digital education, barriers or facilitators, cost evaluation, fidelity, adverse effects, and access to power supply. Finally, incorporation of evidence from low- and middle-income countries should increase generalizability and applicability in those settings.

\section{Strengths and Limitations of the Review}

Strengths of this study include comprehensive searches with no language limitations and robust screening, data extraction, risk of bias assessments, and a critical appraisal of the evidence. Nevertheless, some limitations must be acknowledged while interpreting the results of this systematic review. There was a considerable degree of methodological and clinical heterogeneity in pooled analyses, and the applicability of evaluated evidence might be limited due to high heterogeneity. Additionally, most of the included studies (92\%) reported postintervention data, and we could not calculate pre-post intervention change scores. We also assumed that baseline characteristics including measure scores were adjusted before randomization. Finally, we were unable to obtain additional information from the study authors in six studies that reported mixed participants and mixed results.

\section{Conclusions}

The findings from this review suggest that digital education (standalone or blended with traditional learning) could be as effective as traditional learning (ie, didactic lectures, groups discussions, role play, or oral feedback) in improving postintervention communication skills for medical students. Similarly, more interactive forms of digital education have similar effectiveness or skills outcome compared to less interactive forms of digital education in terms of participant' skills. The overall risk of bias was high, and the quality of evidence ranged from moderate to very low for the reported outcomes. There is a need for further research assessing long-term effectiveness including knowledge or skills retention, other outcomes such as patient-related outcomes, and cost-effectiveness as well as other forms of digital education for medical students' communication skills training.

\section{Acknowledgments}

This review is conducted in collaboration with the Health Workforce Department, World Health Organization. We would also like to thank Mr Carl Gornitzki, Ms GunBrit Knutssön, and Mr Klas Moberg from the University Library, Karolinska Institutet, Sweden, for developing the search strategy and the peer reviewers for their comments. We gratefully acknowledge funding from Nanyang Technological University Singapore, Singapore, for e-learning for health professionals education grant. We would like to thank Associate Professor Josip Car and Dr James Campbell for providing valuable inputs on the manuscript.

\section{Authors' Contributions}

LC, JoC, and PP conceived the idea for the review. SP, PP and BMK wrote the review. LC provided methodological guidance and critically revised the review. JoC and $\mathrm{JaC}$ provided insightful comments on the review.

\section{Conflicts of Interest}

None declared.

\section{Multimedia Appendix 1}

Medline (Ovid) Search Strategy.

[PDF File (Adobe PDF File), 28KB-Multimedia Appendix 1]

\section{Multimedia Appendix 2}

Summary of the findings table for the effects of digital health education on communication skills. [PDF File (Adobe PDF File), 15KB-Multimedia Appendix 2]

\section{Multimedia Appendix 3}

Summary of findings table for the effects of blended digital health education on communication skills. [PDF File (Adobe PDF File), 94KB-Multimedia Appendix 3]

\section{Multimedia Appendix 4}

Summary of findings table for the effects of digital education (more interactive) compared to digital education (less interactive) on communication skills. 


\section{References}

1. Wong SYS, Lee A. Communication Skills and Doctor Patient Relationship. Hong Kong Med Diary 2006 Mar;11(3):7-9.

2. Robinson JD, Hoover DR, Venetis MK, Kearney TJ, Street RL. Consultations between patients with breast cancer and surgeons: a pathway from patient-centered communication to reduced hopelessness. J Clin Oncol 2013 Jan 20;31(3):351-358 [FREE Full text] [doi: 10.1200/JCO.2012.44.2699] [Medline: 23233706]

3. Hasan S. A tool to teach communication skills to pharmacy students. Am J Pharm Educ 2008 Jun 15;72(3):67 [FREE Full text] [doi: 10.5688/aj720367] [Medline: 18698394]

4. Martínez Otero JM. Patients' autonomy and right to the information: from the recognition of rights, to the loss of confidence. Reflections on the new regulation about patients' rights at the end of life [in Spanish]. Cuad Bioet 2012;23(77):151-167 [FREE Full text] [Medline: 22548664]

5. Strasser F, Cerny T. Dealing with ethical dilemmas in oncological communication involving issues of culture and autonomy. Oncology (Williston Park) 2012 Jan;26(1):56, 62, 64 [FREE Full text] [Medline: 22393798]

6. King A, Hoppe RB. "Best practice" for patient-centered communication: a narrative review. J Grad Med Educ 2013 Sep;5(3):385-393 [FREE Full text] [doi: 10.4300/JGME-D-13-00072.1] [Medline: 24404300]

7. Bradley CT, Brasel KJ. Core competencies in palliative care for surgeons: interpersonal and communication skills. Am J Hosp Palliat Care 2007;24(6):499-507. [doi: 10.1177/1049909107310063] [Medline: 18182636]

8. Maeland JG. Changing patients' health behavior--consultation and physician-patient relationship [in Norwegian]. Tidsskr Nor Laegeforen 1993 Jan 10;113(1):47-50. [Medline: 8424251]

9. Berlin L. Informing patients about risks and benefits of radiology examinations utilizing ionizing radiation: a legal and moral dilemma. J Am Coll Radiol 2011 Nov;8(11):742-743. [doi: 10.1016/j.jacr.2011.06.024] [Medline: 22051453]

10. Gramma R, Parvu A, Enache A, Roman G, Ioan B. Truth or lie--some ethical dilemmas in the communication of a severe diagnosis. Rev Med Chir Soc Med Nat Iasi 2013;117(1):172-182. [Medline: 24505911]

11. General Medical Council. 2009. Domain 3 - Communication partnership and teamwork URL: https://www.gmc-uk.org/ ethical-guidance/ethical-guidance-for-doctors/good-medical-practice/domain-3---communication-partnership-and-teamwork [accessed 2019-08-08]

12. Smith S, Hanson JL, Tewksbury LR, Christy C, Talib NJ, Harris MA, et al. Teaching patient communication skills to medical students: a review of randomized controlled trials. Eval Health Prof 2007 Mar;30(1):3-21. [doi: 10.1177/0163278706297333] [Medline: 17293605]

13. Choudhary A, Gupta V. Teaching communications skills to medical students: Introducing the fine art of medical practice. Int J Appl Basic Med Res 2015 Aug;5(Suppl 1):S41-S44 [FREE Full text] [doi: 10.4103/2229-516X.162273] [Medline: 26380210]

14. George PP, Papachristou N, Belisario JM, Wang W, Wark PA, Cotic Z, et al. Online eLearning for undergraduates in health professions: A systematic review of the impact on knowledge, skills, attitudes and satisfaction. J Glob Health 2014 Jun;4(1):010406 [FREE Full text] [doi: 10.7189/jogh.04.010406] [Medline: 24976965]

15. Kyaw BM, Saxena N, Posadzki P, Vseteckova J, Nikolaou CK, George PP, et al. Virtual Reality for Health Professions Education: Systematic Review and Meta-Analysis by the Digital Health Education Collaboration. J Med Internet Res 2019 Jan 22;21(1):e12959 [FREE Full text] [doi: 10.2196/12959] [Medline: 30668519]

16. George PP, Zhabenko O, Kyaw BM, Antoniou P, Posadzki P, Saxena N, et al. Online Digital Education for Postregistration Training of Medical Doctors: Systematic Review by the Digital Health Education Collaboration. J Med Internet Res 2019 Feb 25;21(2):e13269 [FREE Full text] [doi: 10.2196/13269] [Medline: 30801252]

17. Posadzki P, Bala MM, Kyaw BM, Semwal M, Divakar U, Koperny M, et al. Offline Digital Education for Postregistration Health Professions: Systematic Review and Meta-Analysis by the Digital Health Education Collaboration. J Med Internet Res 2019 Apr 24;21(4):e12968 [FREE Full text] [doi: 10.2196/12968] [Medline: 31017584]

18. Ruiz JG, Smith M, van Zuilen MH, Williams C, Mintzer MJ. The educational impact of a computer-based training tutorial on dementia in long term care for licensed practice nursing students. Gerontol Geriatr Educ 2006;26(3):67-79. [doi:

10.1300/J021v26n03_05] [Medline: 16446272]

19. Choules AP. The use of elearning in medical education: a review of the current situation. Postgrad Med J 2007 Apr;83(978):212-216 [FREE Full text] [doi: 10.1136/pgmj.2006.054189] [Medline: 17403945]

20. Higgins JPT, Green S. Cochrane Handbook for Systematic Reviews of Interventions Version 5.1.0. 2011. URL: http:/ /handbook-5-1.cochrane.org/ [accessed 2019-08-08]

21. Car J, Carlstedt-Duke J, Tudor Car L, Posadzki P, Whiting P, Zary N, Digital Health Education Collaboration. Digital Education in Health Professions: The Need for Overarching Evidence Synthesis. J Med Internet Res 2019 Feb 14;21(2):e12913 [FREE Full text] [doi: 10.2196/12913] [Medline: 30762583]

22. Schwan S, Riempp R. The cognitive benefits of interactive videos: learning to tie nautical knots. Learning and Instruction 2004 Jun;14(3):293-305. [doi: 10.1016/j.learninstruc.2004.06.005]

23. Puffer S, Torgerson D, Watson J. Evidence for risk of bias in cluster randomised trials: review of recent trials published in three general medical journals. BMJ 2003 Oct 04;327(7418):785-789 [FREE Full text] [doi: 10.1136/bmj.327.7418.785] [Medline: 14525877$]$ 
24. Cook DA, Hatala R, Brydges R, Zendejas B, Szostek JH, Wang AT, et al. Technology-enhanced simulation for health professions education: a systematic review and meta-analysis. JAMA 2011 Sep 07;306(9):978-988. [doi: 10.1001/jama.2011.1234] [Medline: 21900138]

25. RevMan. Review Manager 5.3. Copenhagen: The Nordic Cochrane Centre: The Cochrane Collaboration; 2014. URL: https://community.cochrane.org/help/tools-and-software/revman-5 [accessed 2019-08-08]

26. Liberati A, Altman DG, Tetzlaff J, Mulrow C, Gøtzsche PC, Ioannidis JPA, et al. The PRISMA statement for reporting systematic reviews and meta-analyses of studies that evaluate health care interventions: explanation and elaboration. J Clin Epidemiol 2009 Oct;62(10):e1-34 [FREE Full text] [doi: 10.1016/j.jclinepi.2009.06.006] [Medline: 19631507]

27. Schünemann HJ, Oxman AD, Higgins JP, Vist GE, Glasziou P, Guyatt GH. Cochrane Handbook for Systematic Reviews of Interventions. 2011. Presenting Results and 'Summary of Findings' Tables URL: https://onlinelibrary.wiley.com/doi/ abs/10.1002/9780470712184.ch11 [accessed 2019-08-15]

28. Bearman M, Cesnik B, Liddell M. Random comparison of 'virtual patient' models in the context of teaching clinical communication skills. Med Educ 2001 Sep;35(9):824-832. [Medline: 11555219]

29. Chittenden E, Anderson W, Lai C, O'Sullivan P. An evaluation of interactive web-based curricula for teaching code status discussions. J Palliat Med 2013 Sep;16(9):1070-1073. [doi: 10.1089/jpm.2012.0611] [Medline: 23937063]

30. Gartmeier M, Bauer J, Fischer MR, Hoppe-Seyler T, Karsten G, Kiessling C, et al. Fostering professional communication skills of future physicians and teachers: effects of e-learning with video cases and role-play. Instr Sci 2015 Apr 7;43(4):443-462. [doi: 10.1007/s11251-014-9341-6]

31. Lanken PN, Novack DH, Daetwyler C, Gallop R, Landis JR, Lapin J, et al. Efficacy of an internet-based learning module and small-group debriefing on trainees' attitudes and communication skills toward patients with substance use disorders: results of a cluster randomized controlled trial. Acad Med 2015 Mar;90(3):345-354. [doi: 10.1097/ACM.0000000000000506] [Medline: 25295964]

32. Lee A, Mader E, Morley C. Teaching cross-cultural communication skills online: a multi-method evaluation. Fam Med 2015 Apr;47(4):302-308 [FREE Full text] [Medline: 25853602]

33. Deladisma AM, Cohen M, Stevens A, Wagner P, Lok B, Bernard T, Association for Surgical Education. Do medical students respond empathetically to a virtual patient? Am J Surg 2007 Jun;193(6):756-760. [doi: 10.1016/j.amjsurg.2007.01.021] [Medline: 17512291]

34. Fleetwood J, Vaught W, Feldman D, Gracely E, Kassutto Z, Novack D. MedEthEx Online: a computer-based learning program in medical ethics and communication skills. Teach Learn Med 2000;12(2):96-104. [doi:

10.1207/S15328015TLM1202 7] [Medline: 11228685]

35. Foster A, Chaudhary N, Murphy J, Lok B, Waller J, Buckley P. The Use of Simulation to Teach Suicide Risk Assessment to Health Profession Trainees-Rationale, Methodology, and a Proof of Concept Demonstration with a Virtual Patient. Acad Psychiatry 2015 Dec;39(6):620-629. [doi: 10.1007/s40596-014-0185-9] [Medline: 25026950]

36. Kaltman S, Talisman N, Pennestri S, Syverson E, Arthur P, Vovides Y. Using Technology to Enhance Teaching of Patient-Centered Interviewing for Early Medical Students. Simul Healthc 2018 Jun;13(3):188-194. [doi: 10.1097/SIH.0000000000000304] [Medline: 29771814]

37. Ruesseler M, Sterz J, Bender B, Hoefer S, Walcher F. The effect of video-assisted oral feedback versus oral feedback on surgical communicative competences in undergraduate training. Eur J Trauma Emerg Surg 2017 Aug;43(4):461-466. [doi: 10.1007/s00068-016-0734-x] [Medline: 27730252]

38. Kron FW, Fetters MD, Scerbo MW, White CB, Lypson ML, Padilla MA, et al. Using a computer simulation for teaching communication skills: A blinded multisite mixed methods randomized controlled trial. Patient Educ Couns 2017 Apr;100(4):748-759 [FREE Full text] [doi: 10.1016/j.pec.2016.10.024] [Medline: 27939846]

39. Tang F, Chen C, Zhu Y, Zuo C, Zhong Y, Wang N, et al. Comparison between flipped classroom and lecture-based classroom in ophthalmology clerkship. Med Educ Online 2017;22(1):1395679 [FREE Full text] [doi: 10.1080/10872981.2017.1395679] [Medline: 29096591]

40. Law GC, Apfelbacher C, Posadzki PP, Kemp S, Tudor Car L. Choice of outcomes and measurement instruments in randomised trials on eLearning in medical education: a systematic mapping review protocol. Syst Rev 2018 May 17;7(1):75 [FREE Full text] [doi: 10.1186/s13643-018-0739-0] [Medline: 29776434]

\section{Abbreviations}

CG: control group

CRCT: cluster randomized controlled trial

GRADE: Grading of Recommendations, Assessment, Development and Evaluations

IG: intervention group

MCQ: multiple-choice questionnaire

OSCE: Objective Structured Clinical Examination

PACT: Problem Affect Concern Treatment

PRISMA: Preferred Reporting Items for Systematic Reviews and Meta-Analyses 
RCT: randomized controlled trial

SMD: standardized mean difference

SP: standardized patient

VP: virtual patient

Edited by A Marusic; submitted 21.12.18; peer-reviewed by M Gartmeier, V Dogas, $M$ Vidak, C Bedard, A Giordano; comments to author 17.01.19; revised version received 30.01.19; accepted 10.07.19; published 27.08.19

Please cite as:

Kyaw BM, Posadzki P, Paddock S, Car J, Campbell J, Tudor Car L

Effectiveness of Digital Education on Communication Skills Among Medical Students: Systematic Review and Meta-Analysis by the Digital Health Education Collaboration

J Med Internet Res 2019;21(8):e12967

URL: http://www.jmir.org/2019/8/e12967/

doi: $10.2196 / 12967$

PMID: 31456579

CBhone Myint Kyaw, Pawel Posadzki, Sophie Paddock, Josip Car, James Campbell, Lorainne Tudor Car. Originally published in the Journal of Medical Internet Research (http://www.jmir.org), 27.08.2019. This is an open-access article distributed under the terms of the Creative Commons Attribution License (https://creativecommons.org/licenses/by/4.0/), which permits unrestricted use, distribution, and reproduction in any medium, provided the original work, first published in the Journal of Medical Internet Research, is properly cited. The complete bibliographic information, a link to the original publication on http://www.jmir.org/, as well as this copyright and license information must be included. 